\title{
Statistical downscaling of climate scenarios over Scandinavia
}

\author{
I. Hanssen-Bauer ${ }^{1, *}$, C. Achberger ${ }^{2}$, R. E. Benestad ${ }^{1}$, D. Chen ${ }^{2,3}$, E. J. Førland ${ }^{1}$ \\ ${ }^{1}$ Norwegian Meteorological Institute, PO Box 43, 0313 Oslo, Norway \\ ${ }^{2}$ Regional Climate Group, Earth Sciences Centre, Göteborg University, PO Box 460, 40530 Göteborg, Sweden \\ ${ }^{3}$ Laboratory for Climate Studies/National Climate Center, China Meteorological Administration, 100081 Beijing, PR China
}

\begin{abstract}
Studies from recent years involving development and application of statistical downscaling models for Scandinavia (mainly Norway and Sweden) are reviewed. In most of the studies linear techniques were applied. Local temperature and/or precipitation were predictands in a majority of the studies. Large-scale temperature fields, either from $2 \mathrm{~m}$ or $850 \mathrm{hPa}$, were found to be the best predictors for local temperature, while a combination of atmospheric circulation indices and tropospheric humidity information were the best predictors for local precipitation. Statistically downscaled temperature scenarios for Scandinavia differ depending on climate model, emission scenario and downscaling strategy. There are nevertheless several common features in the temperature scenarios. The warming rates during the 21st century are projected to increase with distance from the coast and with latitude. In most of Scandinavia higher warming rates are projected in winter than in summer. For precipitation, the spread between different scenarios is larger than for temperature. A substantial part of the projected precipitation change is connected to projected changes in atmospheric circulation, which differ considerably from one model integration to another. A tendency for increased large-scale humidity over Scandinavia still implies that projections for the 21 st century typically indicate increased annual precipitation. This tendency is most significant during winter. In northern Scandinavia the projections tend to show increased precipitation also during summer, but several scenarios show reduced summer precipitation in parts of southern Scandinavia. Comparisons with results from global and regional climate models indicate that both regional modeling and statistical downscaling add value to the results from the global models.
\end{abstract}

KEY WORDS: Local climate scenarios $\cdot$ Temperature $\cdot$ Precipitation $\cdot$ Scandinavia

- Resale or republication not permitted without written consent of the publisher

\section{INTRODUCTION}

In order to assess the various consequences of future climate changes on ecosystems and societies, detailed climate information is needed, both in space and time (e.g. Bergström et al. 2001, Varis et al. 2004). Common global climate models (GCM) provide future climate scenarios at a rather coarse spatial resolution with a grid point spacing of several degrees in latitude and longitude. Though the spatial resolution of the GCMs is steadily improving, the GCM-output is usually post- processed by means of downscaling in order to meet the need for detailed information at local and regional scales in impact assessments. Statistical downscaling (also called empirical downscaling) is a way to infer local information from coarse scale information by applying empirical statistical links between large scale fields and local conditions (e.g. von Storch et al. 2000, Giorgi et al. 2001). Such statistical links may be used both to validate global and regional climate models, and to develop detailed local climate scenarios based upon the output from such climate models. 
Statistical downscaling has been especially recommended in areas with complex topography (Kattenberg et al. 1996). The physio-geographical conditions in Scandinavia cause large climatic gradients even over short distances, e.g. from lowland areas to mountain regions and from the coast to the inland. Further, the reasonably dense network of climate stations with records of $50 \mathrm{yr}$ or more provides a good base for the development of empirical downscaling models. Scandinavia therefore has both the preconditions to develop empirical models and the need to apply them, adding value to the coarse climate scenarios provided by global climate models. Consequently, a number of statistical downscaling studies have been performed for Scandinavia during recent years. The aim of this paper is to review these studies, with particular emphasis on publications that were not covered by the overview of Giorgi et al. (2001). These studies reflect a wide range of different downscaling approaches and tasks; however, the most prominent downscaled variables were temperature and precipitation. Section 2 gives an overview of variables and datasets in these studies, while Section 3 presents the downscaling techniques developed and applied. Section 4 summarizes results from application of the statistical methods for climate scenario downscaling. Added value of statistical downscaling is discussed in Section 5, while further discussion and final conclusions are presented in Section 6.

\section{DATASETS AND VARIABLES}

\subsection{Datasets}

Observationally based data are needed for development and validation of statistical downscaling models. Local meteorological observational series were either downloaded from freely available datasets such as the Nordklim dataset (www.smhi.se/hfa_coord/ nordklim/), or provided directly by the national meteorological institutes. Large-scale meteorological fields were picked from gridded datasets. Both the purely observationally based datasets from the Climate Research Unit (CRU) at the University of East Anglia (New et al. 1999, 2000), and reanalyses from the European Center of Mediumrange Weather Forecast (ECMWF; Gibson et al. 1997) and from the National Center for Environmental Prediction (NCEP; Kalnay et al. 1996, Kistler et al. 2001) were applied.

Output from global or regional climate models forms the basis when statistical downscaling is applied to produce local climate scenarios. An overview of the global climate model integrations used in the Scandinavian studies is given in Table 1. Some of the studies include multi-model comparisons. Chen et al. (2005) used the integrations from the second coupled model intercomparison project (CMIP2), while Benestad (2002a,b, 2003b, 2004a) used 2 ensembles of integrations available from the Intergovernmental Panel on Climate Change (IPCC). Hellström \& Chen (2003) based their downscaling on 2 scenarios from the Rossby Centre regional climate model RCA1 (Rummukainen et al. 2001) in addition to 2 global model scenarios.

\subsection{Predictands}

Statistical downscaling of climate scenarios consists of identifying empirical links between large-scale predictor variables and local predictands (the variables for which local scenarios are developed), and then applying these links to output from climate models. In principle, statistical downscaling models may be developed for any variable for which long, high-quality observational series exist, though the practical value of such models depends on the existence of strong, physically meaningful and temporally stable links between largescale predictors and the predictand. Most of the Scandinavian downscaling studies have so far been focused on monthly mean $2 \mathrm{~m}$ temperature (T2) and/or precipitation $(R)$, but also other variables have been used as predictands (Table 2). Linderson et al. (2004) tried to develop downscaling models for several monthly based predictands related to precipitation (e.g. 75th and 95th percentiles and maximum values for daily precipitation) for southern Sweden, but found skillful models only for $R$ and for frequency of wet days, $\mathrm{f}(R)$. Kaas \& Frich (1995) developed downscaling models for monthly means of daily temperature range $(D T R)$ and cloud cover $(C C)$ for 10 Nordic stations. Reichert et al. (1999) downscaled daily means of $T 2, R, C C$ and relative humidity $(R H)$ at 22 weather stations in western Norway. They argued that daily based models are superior to monthly based models, especially with regards to precipitation, as the actual physical relations between large-scale and local variables are represented less satisfactorily for monthly values. Omstedt \& Chen (2001) and Chen \& Li (2004) developed downscaling models for annual maximum sea ice cover over the Baltic Sea, while Chen \& Omstedt (2005) developed a model for sea level near Stockholm. Even phytoplankton spring bloom in a Swedish lake has been linked to climate predictors and may thus be projected by statistical downscaling (Blenckner \& Chen 2003).

\subsection{Predictors}

- Variables used as large-scale predictors should satisfy several conditions (Giorgi et al. 2001). 
Table 1. Climate model simulations used in statistical downscaling studies for Scandinavia. The first column gives the abbreviation used in this paper. GHG: only the effects of greenhouse gases are included; GSA and GHG: direct effects of industrial aerosols are inclused; GSDIO: effects of greenhouse gases, tropospheric ozone, and direct as well as indirect effects of industrial aerosols are included. CCCma: Canadian Centre for Climate modelling and analysis; DKRZ: Deutsches Klima Rechen Zentrum; UKMO: United Kingdom Met Office

\begin{tabular}{|c|c|c|c|c|c|c|}
\hline Abbreviation & Model name & $\begin{array}{l}\text { Model } \\
\text { centre }\end{array}$ & $\begin{array}{l}\text { Effects } \\
\text { included }\end{array}$ & $\begin{array}{l}\text { Emission } \\
\text { scenario }\end{array}$ & Model literature source & Source $^{a}$ \\
\hline CGCM1 & CGCM1 & CCCma & GSA & IS92a & $\begin{array}{l}\text { Boer et al. (2000), } \\
\text { Flato et al. (2000) }\end{array}$ & 21 \\
\hline $\mathrm{ECH} 1$ & ECHAM-1 & DKRZ & GHG & $\begin{array}{l}\text { Business } \\
\text { as usual }\end{array}$ & Cubasch et al. (1992) & 20 \\
\hline ECH4-a & ECHAM4/MLO & DKRZ & GHG & $\begin{array}{l}1 \times \mathrm{CO}_{2} \text { vs. } \\
\text { preindust. }\end{array}$ & Roeckner et al. $(1996,1999)$ & 23 \\
\hline $\mathrm{ECH} 4-\mathrm{b}$ & ECHAM4/OPYC3 & DKRZ & GHG & IS92a & $\begin{array}{l}\text { Roeckner et al. (1996) } \\
\text { Oberhuber (1993) }\end{array}$ & $1,2,17,18$ \\
\hline $\mathrm{ECH} 4-\mathrm{C}$ & ECHAM4/OPYC3 & DKRZ & GSDIO & IS92a & $\begin{array}{l}\text { Roeckner et al. (1996) } \\
\text { Oberhuber (1993) }\end{array}$ & $3,14,15,16$ \\
\hline HadCM2 & HadCM2 & UKMO & GHG & $\begin{array}{c}1 \times \mathrm{CO}_{2} \text { vs } \\
2.5 \times \mathrm{CO}_{2}\end{array}$ & Johns et al. (1997) & $10,17,18$ \\
\hline \multirow[t]{3}{*}{ CMIP2 } & 17 models & Several & GHG & $+1 \% /$ year & Meehl et al. (2000) & 13 \\
\hline & $\begin{array}{l}17 \text { integrations, } \\
10 \text { models }\end{array}$ & Several & GSA, GSDIO & IS92a & & $4,5,7$ \\
\hline & $\begin{array}{l}14 \text { integrations, } \\
7 \text { models }\end{array}$ & Several & GSA, GSDIO & IS92a & & 6 \\
\hline
\end{tabular}

- They should account for a major part of the variability in the predictands.

- The links between predictors and predictands should be temporally stable.

- When used for downscaling from climate models, it is also important that the large-scale predictors are realistically reproduced by the global (or regional) climate model which is applied.

- In a changing climate, it is further crucial that the predictors 'fully represent the climate change signal', e.g. an indicator for the radiative properties of the atmosphere should be included when downscaling $T 2$, while humidity information is crucial when downscaling $R$ (von Storch et al. 2000).

Here, predictors which have been used in the Scandinavian studies (Table 2) will be discussed with respect to these conditions.

\subsubsection{Predictors related to atmospheric circulation}

Atmospheric circulation strongly influences the local climate. In Scandinavia, sea level pressure (SLP) fields, or circulation indices based upon SLP (e.g. zonal and meridional wind and vorticity: $u, v$, and $\xi$ ) have been demonstrated to account for a large part of the variation and trends in local $T 2$ and $R$ on timescales from months to decades, especially in autumn and winter (Chen \& Hellström 1999, Chen 2000, Hanssen-Bauer \& Førland 2000, Busuioc et al. 2001a,b). Even variability in aquatic ecosystems is associated with SLP variability (Blenckner \& Chen 2003).

Several Scandinavian studies include evaluation of the temporal stability of the links between local T2 or $R$ and atmospheric circulation during the 20th century. Though links between T2 and the North Atlantic Oscillation (NAO) index were found to be temporally unstable (Chen \& Hellström 1999), links between $T 2$ or $R$ and more complex and regionally based circulation indices seem to be stable in time (Benestad 2001a, Busuioc et al. 2001b, HanssenBauer \& Førland 2001). Nevertheless, the ability of circulation indices alone to account for long-term or decadal variability, especially for T2 but also for $R_{,}$ varies with time (Hanssen-Bauer \& Førland 2000, Benestad 2001a). Additional predictors thus have to be included, not only to project a possible future climate change, but also to describe climate development in the past. Additional predictors are suggested in Section 2.3.2.

The performance of the state-of-the-art global climate models in reproducing the SLP field over the northern North Atlantic and Scandinavia is reasonably good. Busuioc et al. (2001b) validated the SLP-fields 
Table 2. Statistical downscaling studies in Scandinavia. Source: identification number (used in Table 1) and literature reference(s) for the study. $C C$ : cloud cover; DTR: daily temperature range; freq $(R)$ : frequency of days with precipitation; $H$ : humidity; H500: height of 500 hPa; $H 500 / 700$ : thickness between 500 and $700 \mathrm{hPa}$; H500/1000: thickness between 500 and $1000 \mathrm{hPa}$; : absolute air humidity; R: precipitation; RH: relative air humidity; SLP: sea level pressure; SST: sea surface temperature; T: temperature; T2: $2 \mathrm{~m}$ temperature; T500: temperature in 500 hPa; T850: temperature in $850 \mathrm{hPa}$; Td: dewpoint temperature; CCA: canonical correlation analysis; EOF: empirical orthogonal function; MLR: multiple linear regression. Time resolution: M: monthly; D: daily

\begin{tabular}{|c|c|c|c|c|c|}
\hline Source & Predictands & Large-scale predictors & Method & $\begin{array}{l}\text { Time } \\
\text { resolution }\end{array}$ & $\begin{array}{l}\text { Future } \\
\text { scenario }\end{array}$ \\
\hline 1. Benestad (1999) & $T 2, R$ & T2, T500, SLP, H500, SST & CCA (EOF-based) & M & Yes \\
\hline 2. Benestad (2001a) & $\mathrm{T} 2$ & T2, H50O, SLP & CCA (EOF-based) & $\mathrm{M}$ & Yes \\
\hline 3. Benestad (2001b) & $T 2$ & SLP, T2 & CCA (EOF-based) & M & Yes \\
\hline 4. Benestad (2002a) & $T 2$ & T2, T850, H500/700 & CCA (EOF-based) & M & Yes \\
\hline 5. Benestad (2002b) & $T 2, R$ & T2, T850, H500/700, SLP & CCA (EOF-based) & M & Yes \\
\hline 6. Benestad (2003b) & $T 2$ & $T 2$ & CCA (EOF-based) & M & No \\
\hline 7. Benestad (2004a) & $T 2$ & T2, T850, H500/700 & CCA (EOF-based) & M & Yes \\
\hline 8. Blenckner \& Chen (2003) & $\begin{array}{c}T 2, T \text { (water) ice, } \\
\text { phenol., ecol. in lake }\end{array}$ & SLP & MLR (direct) & M & No \\
\hline 9. Busuioc et al. (2001a) & $R$ & SLP & CCA (direct) & M & No \\
\hline 10. Busuioc et al. (2001b) & $R$ & SLP & CCA (direct) & M & Yes \\
\hline 11. Chen \& Chen (1999) & $T 2$ & SLP & MLR (direct) & M & No \\
\hline 12. Chen (2000) & $T 2$ & SLP & MLR (direct) & M & No \\
\hline 13. Chen et al. (2005) & $R$ & $\mathrm{SLP}, R$ & MLR (direct) & M & Yes \\
\hline $\begin{array}{l}\text { 14. Hanssen-Bauer \& } \\
\text { Førland }(2000,2001)\end{array}$ & $T 2$ & SLP & MLR (EOF-based) & M & No \\
\hline 15. Hanssen-Bauer et al. (2001) & $R$ & SLP, T2 & MLR (EOF-based) & M & Yes \\
\hline 16. Hanssen-Bauer et al. (2003) & $T 2, R$ & $T 2$, SLP, T2 & $\begin{array}{l}\text { Scaling (direct) } \\
\text { MLR (EOF-based) }\end{array}$ & M & Yes \\
\hline 17. Hellström et al. (2001) & $R$ & SLP, $q 850$ & MLR (direct) & M & Yes \\
\hline 18. Hellström \& Chen (2003) & $R$ & SLP, $q 850$ & MLR (direct) & M & No \\
\hline 19. Imbert \& Benestad (2005) & $T 2, R$ & T2, SLP & Analogue (EOF-based) & $\mathrm{D}$ & Yes \\
\hline 20. Kaas \& Frich (1995) & $D T R, C C$ & $H 500, H 500 / 1000$ & MLR (EOF-based) & M & Yes \\
\hline 21. Linderson et al. (2004) & $R$, freq $(R)$ & $\mathrm{SLP}, R H, R$ & MLR(direct) & M & Yes \\
\hline $\begin{array}{l}\text { 22. Omstedt \& Chen (2001), } \\
\text { Chen \& Li (2004) }\end{array}$ & Sea ice ext. & SLP & MLR (direct), Wavelet & M & No \\
\hline 23. Reichert et al. (1999) & $T 2, R, C C, T d$ & $\begin{array}{c}T 2, T d, H \text { and } R H \text { from } \\
\text { several levels, SLP, } R, \text { conv. } \\
R, C C \text {, total water vapour }\end{array}$ & MLR (direct) & $\mathrm{D}$ & $\begin{array}{c}\text { No } \\
\text { (Pre- } \\
\text { industrial) }\end{array}$ \\
\hline 24. Wetterhall et al. (2005) & $R$ & SLP & $\begin{array}{c}\text { Analogue (EOF-based } \\
\text { and Teweles-Wobus score) }\end{array}$ & M, D & No \\
\hline
\end{tabular}

simulated by HadCM2, and concluded that large-scale SLP variability is very well reproduced in autumn, winter and spring, and reasonably well in summer. Hanssen-Bauer \& Førland (2001) similarly validated ECH4-C and concluded that though the north-south SLP gradient over the Atlantic-European region on average is weaker than observed, the observed SLP anomalies are reproduced very well.

For several predictands, SLP based predictors thus satisfy all but the last of the above mentioned conditions, and they were therefore used in many of the Scandinavian downscaling studies. Reichert et al. (1999), however, applied circulation indices based upon geopotential height fields, and concluded that the vertical velocity at $850 \mathrm{hPa}$ as well as $u$ and $\xi$ at $700 \mathrm{hPa}$ account for a major part of the variability in daily precipitation in western Norway.

\subsubsection{Signal bearing predictors}

In their downscaling study of $C C$ and $D T R$, Kaas \& Frich (1995) stated that inclusion of tropospheric temperature information among the predictors is crucial for estimating greenhouse gas induced changes. They used the 500 to $1000 \mathrm{hPa}$ thickness (H500/1000) as a predictor in addition to the SLP field. Reichert et al. (1999) tested several predictors (Table 2) and found that temperature and relative humidity at $850 \mathrm{hPa}$ (T850 and RH850) are useful predictors for local T2. They preferred upper air predictors, as they thought that low spatial resolution in global climate models may lead to less realistic near-surface fields. Benestad (2004a), however, validated the large-scale T2 field over the North Atlantic region in 17 global climate model integrations and concluded that most models 
produce realistic spatial T2 patterns. Benestad (1999, 2002a) warned against applying upper air parameters as the only predictors, as the vertical structure of the atmosphere may change in a changing climate, making the links between upper air predictors and surface predictands unstable. He found that using $H 500$ and T500 as predictors gave unrealistic local T2 trends. It may also be difficult to find long series of high quality upper air data for developing and validating statistical models. There has been some debate surrounding temperature trends in the free troposphere, and according to Seidel et al. (2004) it is not yet possible to establish the magnitude of this trend with certainty. Benestad (1999) agreed with Reichert et al. (1999) that T850 was a good predictor for local T2 in Scandinavia, but concluded that the T2 field was just as good a predictor.

Benestad (1999) concluded that the observed sea surface temperature (SST) field in some areas is also a good predictor for local winter temperature, but warned against downscaling T2 from GCM SST fields, as they are often associated with large uncertainties in terms of their regional character. Benestad et al. (1999) documented regional misrepresentations of the SST in the control integration of ECHAM4/OPYC3 model, while Benestad et al. (2002) found that regional biases in both SST and sea-ice extent also represent a problem in more recent state-of-the art GCM integrations.

Hanssen-Bauer \& Førland (2001) evaluated the T2 fields over Scandinavia simulated by the ECH4-C model. They concluded that both the large scale T2 fields and the observed links between large-scale SLP and $T 2$ are well reproduced, especially during winter. This may explain why Hanssen-Bauer et al. (2003) found that applying the SLP field as a predictor for T2 in addition to the T2 field did not improve the local T2 estimates significantly.

Several potential 'signal-bearing' predictors have been tested for downscaling precipitation. Reichert et al. (1999) used a stepwise statistical procedure to select predictors from a large number of candidates. The final choice of predictors varied from station to station, but the only selected predictors which contained information on humidity were $R H$ at 2 levels. However, $R H$ does not really carry the whole 'climate signal' as additional information about temperature is needed to know the amount of precipitable water. Though the model developed by Reichert et al. (1999) worked well over the 15 yr development plus validation period, the precipitation was slightly overestimated in the validation period, which on average was colder than the development period. The model may thus miss longterm trends connected to global warming. Hellström et al. (2001) used large-scale absolute humidity at $850 \mathrm{hPa}$ (q850) as a predictor for precipitation, in addi- tion to circulation indices. They concluded that changes in $q 850$ seem to be the major contributor to the projected long-term precipitation changes. Hanssen-Bauer et al. $(2001,2003)$ tested $T 2$ as a 'signal bearing' predictor for $R$. T2 was regarded as a proxy for precipitable water in the troposphere and could thus to some degree make up for not including air humidity as a predictor. In summer, however, the inclusion of $T 2$ as a predictor for $R$ led to unrealistic results. Consequently in the final models T2 was not applied as a predictor during the summer months. Linderson et al. (2004) tested several predictors both for $R$ and $\mathrm{f}(R)$, including large-scale $R, q 850, R H 850, T 850$ and a thermal stability index. They concluded that large-scale $R$ and $R H 850$ were the most useful predictors in addition to the SLP based predictors. $R H$ was more important than $R$ for downscaling $\mathrm{f}(R)$, while large-scale $R$ was more important for downscaling $R$.

All precipitation studies cited above conclude that predictors representing atmospheric circulation have to be applied in addition to the signal bearing predictor(s). The reason for this may partly be that local distribution of $R$ is highly dependent on atmospheric circulation, but also that the state-of-the-art global climate models in general do not simulate humidity related variables like $q$ and $R$ very well (McAvaney et al. 2001). Specifically, Busuioc et al. (2001b) showed that the observed links between the SLP field and $R$ over Sweden were not satisfactorily reproduced by HadCM2. The links were reasonably well reproduced in autumn and winter, but not in spring and summer. Inclusion of atmospheric circulation related predictors in the downscaling models may thus add value to the local projections, not only by adding information relevant for describing the local effects of topography, but also by introducing largescale empirical links which are not captured by the global climate models.

\section{DOWNSCALING METHODS AND STRATEGIES}

Surveys of methods for establishing links between predictors and predictands are provided by e.g. Wilby \& Wigley (1997), von Storch et al. (2000), Giorgi et al. (2001) and Fan et al. (2005). In most of the Scandinavian studies, the linear methods Multiple Linear Regression (MLR) and Canonical Correlation Analysis (CCA) were applied in combination with a stepwise screening process to pick the best set of predictors (Table 2). In 2 studies, however, non-linear analog model strategies were developed, as proposed by Zorita \& von Storch (1999).

In some studies grid-point values, or indices based upon a fixed number of grid-point values, were 
applied directly as predictors. In other studies, empirical orthogonal functions (EOFs, e.g. North et al. 1982) based upon the predictor fields within a certain domain were applied.

An advantage of using large-scale variables directly as predictors is that the effect on the predictand of each individual predictor is easily seen, which may simplify the physical interpretation of the results. Chen (2000) defined 6 large-scale atmospheric circulation indices from 16 grid-point SLP values, following the interpretation by Briffa (1995) of the weather classification scheme developed by Lamb (1950). These indices were applied in several MLR studies, either alone or combined with grid-point values representing other predictors (Chen \& Chen 1999, Linderson et al. 2004). Reichert et al. (1999) defined circulation indices also based upon upper air fields. Hanssen-Bauer et al. (2003) used grid-point $T$ values directly as a predictor for local $T$ in a scaling procedure based on observed spatial variability within formerly defined temperature regions.

Instead of applying the predictor variables directly, it is possible to train the downscaling models on the leading EOFs calculated from the single or combined large-scale predictor fields over a given domain. An advantage of this approach is that the different EOFs are orthogonal, while the original predictors usually are inter-correlated. Kaas \& Frich (1995) applied combined EOFs as predictors, and developed scenarios by projecting the modeled predictor fields onto the observed EOFs. Benestad (2001b) suggested, as an alternative to this projection, the so-called commonEOF approach, where the spatial patterns associated by the principal components are the same in the observations as in the model simulations. He found that though the results on average were similar, common EOFs seemed to give more stable results. Common EOFs were applied in a majority of the EOF based studies in Table 2. Benestad (2003a, 2004b) developed the software tool 'clim.pact' for calculating single or combined common EOFs from relevant fields and applying them to develop statistical downscaling models.

The choice of predictor domain (size and position) affects the downscaling results. Benestad (2002a) demonstrated that the predictand stations should be situated well within the predictor domain. Concerning domain size, Benestad (2002b) noted that domains that were too large lead to an underestimation of long-term temperature trends. On the other hand, the area should be sufficiently large to include the spatial scale on which the global climate models give useful information. Wetterhall et al. (2005) concluded that the optimal domain size depends on time-resolution and predictors. Specifically they noted that the opti- mum size is larger for daily values than for monthly values.

Analogue model strategies were developed by Imbert \& Benestad (2005) for downscaling daily temperature and precipitation from large-scale temperature and SLP, and by Wetterhall et al. (2005) for downscaling of daily and monthly precipitation from SLP. Imbert \& Benestad (2005) used common EOFs as predictors and found that weighted principal components give more realistic results than unweighted ones in the analogue model. Wetterhall et al. (2005) explored the possibility of using the 'Teweles Wobus score' (TWS) as predictor, as an alternative to EOFs. TWS is based on the 'shape' of the pressure fields described by the pressure gradients in the $x$ - and $y$-directions in each grid point. Wetterhall et al. (2005) concluded that the TWS scores performed equally as well as the more traditional analogue method and recommended it for future studies. A shortcoming of analogue models is their incapability of making extrapolations outside the range of observed values. Even for a stable climate, it is expected that new records are set over time, and thus caution must be taken when using the analog model for studying extremes (the tails of the distribution; Benestad 2003c). Imbert \& Benestad (2005) suggest a combined method including superimposing a trend from a linear study onto the results of the analog model.

At present, studies (D. Chen et al. unpubl. data) are also underway to develop and apply weather generators (WG) to Scandinavian conditions. The method suggested by Liao et al. (2004) is being applied, and both existing and new monthly scenarios will be used for developing daily climate scenarios. As only preliminary results exist from these studies so far, they will not be discussed further in the present paper.

Few direct comparisons of results from different downscaling techniques have been performed in Scandinavia. Benestad (1999) compared the linear techniques MLR, CCA and Singular Value Decomposition (SVD), and concluded that overall no method is superior to the others as long as the information content in the predictors is similar. Choice of predictors, predictor domains and other strategic choices are more critical for the results than the choice of linear technique. Results from the non-linear models are sparse, and they have not yet been systematically compared to results from the linear models. It is clear that the analog method is superior to the linear techniques for producing a realistic level of variance, especially for precipitation (e.g. Imbert \& Benestad 2005), but it remains to be seen whether application of historical analogs can produce the expected future climatic trends. 


\section{DOWNSCALED CLIMATE SCENARIOS FOR SCANDINAVIA}

\subsection{Temperature scenarios}

Benestad (2002a,b, 2004a) downscaled temperature scenarios for localities in northern Europe using 17 climate simulations from 10 different global climate models under the emission scenario IS92a. A total of 48 downscaled temperature scenarios were produced by using different global simulations, predictors and domains. The models show a considerable spread concerning projected warming rates, but some results seem to be robust. The projected warming rates are generally larger inland than along the coast (e.g. Fig. 1; coastal stations are Ona and Vardoe, inland stations are Nesbyen and Karasjok). The 48 scenario ensemble mean projected January warming rate during the 21 st century increases from $<0.3^{\circ} \mathrm{C}$ per decade along the west coast of Norway to $>0.5^{\circ} \mathrm{C}$ per decade in inland areas in Sweden, Finland and Norway (Benestad 2002a,b). In Denmark the mean projected January warming rates range from 0.3 to $0.4^{\circ} \mathrm{C}$ per decade. Benestad (2004a) presented the same results in terms of probability, and concluded that under IS92a the probability of a January warming of $\geq 0.5^{\circ} \mathrm{C}$ per decade was $<10 \%$ along the Norwegian west coast, about $20 \%$ in Denmark, but $>70 \%$ in some inland areas in Sweden and Finland. In Scandinavia, except for the southernmost parts and the western coast of southern Norway, another robust signal in the projections is that the warming rates are larger in winter than in summer, e.g. in Oslo, Norway, $80 \%$ of the projected January warming rates are between 0.30 and $0.70^{\circ} \mathrm{C}$ per decade while the range in July is between 0.05 and $0.35^{\circ} \mathrm{C}$ per decade (Benestad 2004a). Several models also show a tendency for larger winter and spring warming rates at higher latitudes, though distance to the open sea seems to be more important than latitude.

Hanssen-Bauer et al. (2003) downscaled a temperature scenario for Norway based upon the integration of ECH4-c. They concluded that warming rates will be higher in winter than in summer, inland than along the coast, and in the north than in the south, in agreement with Benestad (2002a,b, 2004a). Hanssen-Bauer et al. (2003) found regional winter (DecemberJanuary-February) warming rates of 0.3 to $0.6^{\circ} \mathrm{C}$ per decade, and summer (June-July-August) warming rates of 0.2 to $0.3^{\circ} \mathrm{C}$ per decade. They also found variation within the regions; larger winter and spring warming was projected in inland valleys than in the mountains. Hanssen-Bauer et al. (2003) argued that the faster warming in the valleys is physically consistent with a projection of (1) a larger reduction in the winter and spring snow cover on the valley floor than in the mountains, (2) increased wind speeds and (3) increased cloud cover. All these features contribute to a reduced frequency and intensity of winter temperature inversions.

Benestad (2001a) examined the cause of the warming over Norway projected by ECH4-b. He concluded that although changes in atmospheric circulation can account for decadal scale trends in winter temperatures during some periods,
Fig. 1. Projected changes $\left({ }^{\circ} \mathrm{C}\right)$ in January temperatures $(2 \mathrm{~m}$ temperatures, T2) at 13 Norwegian localities from 2000 to 2050 according to 48 statistically downscaled scenarios based upon 17 GCMs. The boxes show the interquartile range, while the whiskers extend to the most extreme data point that is no more that 1.5 times the interquartile range from the box. Figure adapted from Benestad (2002b) 
they cannot account for the projected centurial trend. Hanssen-Bauer \& Førland (2001) similarly conclude that though changes in the SLP field projected by ECH4-c locally contribute to the projected future warming in the winter season, the major part of the warming is not linked to changes in the SLP field.

\subsection{Precipitation scenarios}

Some statistically downscaled scenarios for precipitation were produced applying only SLP-based predictors (Busuioc et al. 2001b, Benestad 2002b). These may be used to evaluate possible consequences for future precipitation of changes in the atmospheric circulation. Busuioc et al. (2001b) concluded that the changes in atmospheric circulation projected by HadCM2 lead to increased precipitation in Sweden in the autumn, and also in NE Sweden in the winter. Benestad (2002b), using a multi-model study, found that projected changes in atmospheric circulation varied substantially from model to model, and so too did the circulation-induced precipitation changes. He concluded that the lack of clear trends in projected precipitation probably were due to the fact that the effect of increased humidity was not taken into account. In order to estimate the total effect of increased concentrations of greenhouse gases on precipitation conditions, the rest of this section is focused on precipitation studies including humidity related predictors.

Hellström et al. (2001) used $u, v, \xi$ and $q 850$ to deduce precipitation scenarios for Sweden from the global models HadCM2 and ECH4-b. Changes in precipitation conditions were projected by studying the differences between $10 \mathrm{yr}$ control and scenario timeslices. In ECH4-b the $\mathrm{CO}_{2}$ concentration in the scenario time-slice was twice the control concentration and in HadCM2, $\mathrm{CO}_{2}$ concentrations were somewhat greater (Table 1). The modelled increases in global mean temperature from control to scenario time-slices were nevertheless almost the same. The downscaled precipitation scenarios for winter and spring show increased precipitation in northern and NW Sweden $(\sim 20 \%)$ and reduced precipitation ( - 20\%) in southern Sweden. During autumn both models projected a substantial increase in NW Sweden, but only minor changes in southernmost Sweden. During summer HadCM2 projected a substantial increase all over the country, while ECH4-b indicated an increase in northern and a reduction in central and southern Sweden. Hellström et al. (2001) concluded that change in $\xi$ was the greatest contributor to the projected precipitation changes in southern Sweden, while changes in the humidity had greater effect in the northern parts of the country, e.g. the modelled reduction in spring and win- ter precipitation in southern Sweden is linked to reduced $\xi$, while the projected all-season precipitation increase in northern Sweden mainly is attributed to increased $q 850$.

Based on the Canadian model CGCM1, Linderson et al. (2004) established scenarios of $R$ and freq $(R)$ for a region in southern Sweden under emission scenario IS92a up to the year 2100. RH850, $R, u, v$ and $\xi$ were applied as predictors. The downscaled scenario showed a significant increase in the annual mean precipitation $(\sim 10 \%)$ and a slight decrease $(\sim 1.5 \%)$ in the frequency of wet days. The results indicate an increase in precipitation intensity almost year round, but especially during winter. The mean precipitation increases from November to March and decreases slightly from April to August. A corresponding increase in the frequency of wet days occurs between December and March while the decrease occurs in April to November. The increase in precipitation during winter and spring is associated with an increase in westerly flow and vorticity, but also with an increase in the large-scale precipitation. The summer decrease is linked to a decrease in vorticity and westerly flow and an increase of northerly flow.

Hanssen-Bauer et al. $(2001,2003)$ downscaled the integration ECH4-C over Norway. They studied changes between the time-slices 1980-1999 to 2030-2049. SLP and T were applied as predictors in all seasons except in summer, when only SLP was used. The projection showed an increase in annual precipitation of 0.3 to $2.7 \%$ per decade in different Norwegian regions up to 2050 . The projected increase was statistically significant $(5 \%$ level) in all regions except the southeast. In autumn and winter the precipitation increase was statistically significant almost everywhere. In autumn the increase exceeded $2.5 \%$ per decade in the western and NW regions. In winter it exceeded $2.5 \%$ per decade in the southern regions. The spring-time precipitation trends tended to be negative in southern Norway and positive in northern Norway. The negative trends were statistically significant in the SE regions. In summer the analysis also yielded a negative trend in precipitation in SE regions, but a statistically significant increase in summer precipitation was projected along the west coast of Norway. Hanssen-Bauer et al. (2001) concluded that increased temperature and thus increased precipitable water contributed to the projected precipitation increase all over the country during autumn and winter. Projected changes in atmospheric circulation nevertheless accounted for a substantial part of the increase in the regions with largest projected increase, e.g in western regions during autumn, and in southern regions during winter. In spring, circulation induced changes dominated in southern regions, while increased precip- 
itable water was more important in northern regions. In summer, the model only accounted for circulation induced changes.

Chen et al. (2005) downscaled precipitation scenarios for Sweden based on the 17 models in CMIP2, using $R$, $u, v$ and $\xi$ as predictors. They compared the precipitation conditions during Years 50-80 in the scenario period (in CMIP2 the doubling of $\mathrm{CO}_{2}$ occurs in Year 70) with an $80 \mathrm{yr}$ control run, and concluded that though there was a substantial spread between individual scenarios, the ensemble of scenarios suggested an overall increase in annual precipitation (Fig. 2). The increase in precipitation was more significant in northern than in southern Sweden. This overall positive trend could be attributed to the increased large-scale precipitation and the westerly wind. The seasonal precipitation in autumn, winter and spring was expected to increase, whereas there was an indication of decreasing summer precipitation in the southern half of the country. The estimated uncertainty was nearly independent of region. However, there was a seasonal dependence: the estimates for winter showed the highest level of confidence, and the estimate for summer the lowest.

\subsection{Other variables}

Kaas \& Frich (1995) downscaled DTR and CC at 10 synoptic stations including 6 in Scandinavia using

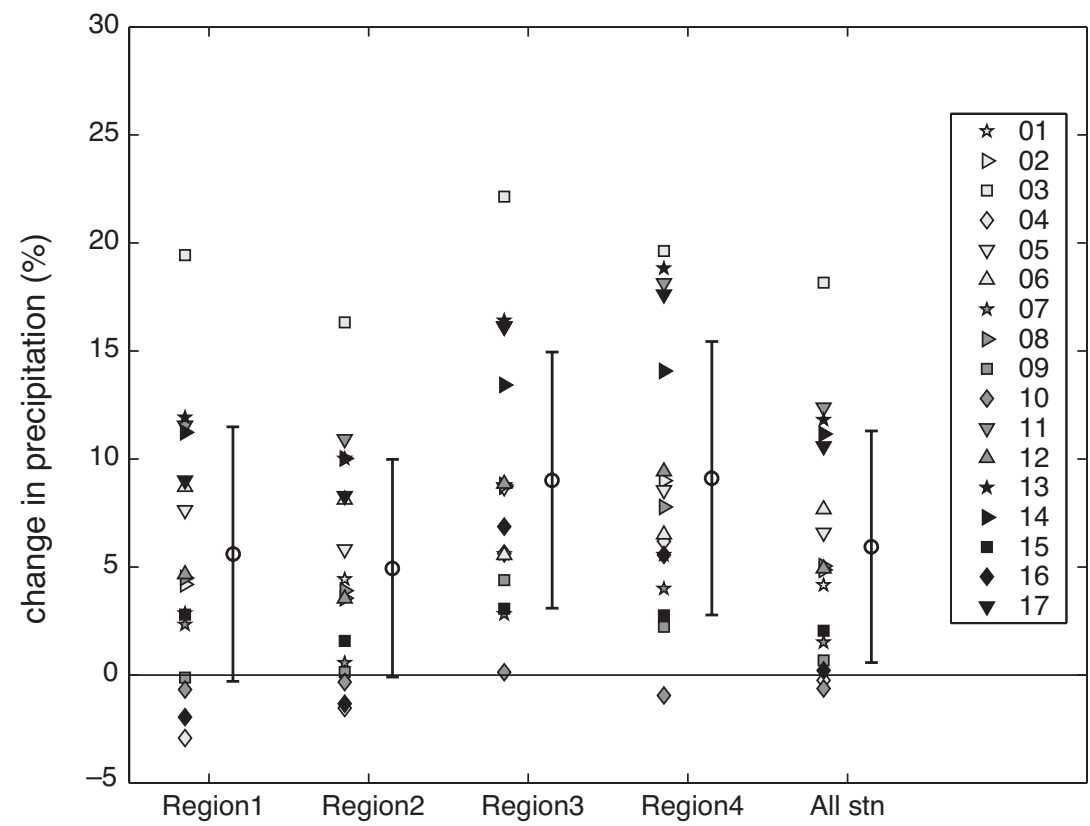

Fig. 2. Projected changes (\%) in annual precipitation for 4 Swedish regions and for all of Sweden under doubled $\mathrm{CO}_{2}$ concentration according to statistical downscaling of 17 GCM scenarios. Region 1: southernmost; Region 2: mid-south; Region 3: mid-north; Region 4: northernmost. Vertical bars show mean \pm SD. From Chen et al. (2005)
H500 and H500/1000 as predictors. The final $30 \mathrm{yr}$ of a control simulation of the 20th century were compared to the final $30 \mathrm{yr}$ of a scenario 'A' (business as usual) simulation of the 21st century generated by ECH1. Kaas \& Frich (1995) found that statistically significant negative trends in DTR were projected for Fennoscandia (Finland, Sweden and Norway), especially in central and eastern areas, and especially during winter. Positive trends in cloud cover were projected over most of the area; these were most significant in NE areas of Fennoscandia.

Though downscaling models have been developed also for other variables in Scandinavia, future scenarios have not been constructed from these. Downscaled $T$ scenarios have, however, been applied to develop scenarios for growing, heating and freezing indices. Skaugen \& Tveito (2004) found that, according to a downscaled $T$ scenario based upon the ECH4-c model, the growing season will increase in all parts of Norway up to 2050, but local differences will be large. The projected change in the growing season is sensitive not only to the projected change in $T$, but also highly dependent on the present local $T$ level and seasonal amplitude. Skaugen \& Tveito (2004) concluded that the projected growing season increase over $60 \mathrm{yr}$ is $<3 \mathrm{wk}$ in the northernmost inland region and $>6 \mathrm{wk}$ in some coastal areas, even though the projected $T$ increase is considerably larger in the inland than along the coast. Førland et al. (2004) projected changes in growing, heating and freezing indices for a number of localities, including stations in the Scandinavian countries, during the same period. Their projections indicate a 3-4 wk increase in the growing season and a $2-4$ wk reduction in the heating season at most of the Scandinavian sites. The projected reduction in the freezing season was 2-5 wk in the northern inland, but considerable longer at coastal and southern sites.

\subsection{Uncertainty of downscaled climate scenarios}

Uncertainties associated with emission scenarios, internal variability of the climate system, GCMs and statistical downscaling models all contribute to the uncertainty of downscaled climate scenarios (Benestad 2001b, Chen et al. 2005). The spread of scenarios estimated by different emission scenarios, initial conditions, GCMs and downscaling models and strategies is not an absolute measure for this uncertainty. Different GCMs or downscaling models 
may all be biased by the same shortcomings, and thus show only a fraction of the real uncertainty. On the other hand inclusion of improbable emission scenarios or initial conditions, or less realistic GCMs or downscaling models may lead to the inclusion of unrealistic climate scenarios in the ensembles. The spread of ensembles of scenarios may nevertheless indicate the magnitude of the uncertainty and the relative influence of different sources.

Benestad (2002a,b) found that the interquartile range of the projected changes in local monthly mean temperatures from 2000 to 2050 typically varied from $<1^{\circ} \mathrm{C}$ along the coast to $>2^{\circ} \mathrm{C}$ at some inland localities for his 48 scenario ensemble (e.g. Fig. 1). The spread was smaller for seasonal and annual temperature scenarios than for monthly values. Benestad (2002b) concluded that, apart from a few GCMs which did not seem to perform well over Scandinavia, the spreads arising from using different global scenarios and the use of different downscaling strategies are similar. The spread caused by different downscaling strategies would, however, be smaller if the use of upper air predictors and the largest predictor domain were omitted. The spread between different global scenarios is caused partly by natural internal climate variability and partly by differences between the GCMs. The effect of different emission scenarios is minor in the above results as Benestad (2002a,b) used global projections based upon rather similar emission scenarios. Preliminary results from downscaling of the SRES scenarios A2 and B2 (I Nakićenović et al. 2000), however, shows that different emission scenarios lead to considerable differences in local temperature scenarios in Scandinavia towards the end of the 21st century (Benestad 2004c).

Chen et al. (2005) found a substantial spread in their 17 scenarios for annual precipitation in Sweden at doubled $\mathrm{CO}_{2}$ (Fig. 2), even though uncertainty associated with the downscaling procedure did not contribute to the spread (only 1 statistical downscaling strategy is applied by Chen et al. [2005]). Benestad (2002b) found that uncertainties in monthly and annual precipitation scenarios associated with GCM realisations tended to be greater than those associated with the downscaling strategies as long as the predictors were the same. Thus, while the spread of the global scenarios accounts for only about $50 \%$ of the spread of projected local temperature trends, it accounts for a major part of the spread of projected local precipitation trends (Benestad 2002b). One reason for this is probably that differences between the global scenarios concerning projected changes in atmospheric circulation over Fennoscandia, which are considerable, greatly influence the projected local precipitation trends (e.g. Hanssen-Bauer et al. 2001, Hellström et al. 2001, Lin- derson et al. 2004), while the projected temperature trends are, to a lesser degree, affected by differences in atmospheric circulation alone (e.g. Benestad 2001a, Hanssen-Bauer \& Førland 2001).

\section{ADDED VALUE AND COMPARISON WITH REGIONAL MODELING}

Some of the Scandinavian studies include comparisons of present climate global and regional model output, statistically downscaled values and observations. Hellström et al. (2001) and Hanssen-Bauer et al. (2003) found that the seasonal precipitation cycle over Scandinavia is poorly simulated by the global models HadCM2 and/or ECH-b and c. Both these studies concluded that regional modelling as well as statistical downscaling improves the description of the seasonal precipitation variability considerably. Further, they concluded that observed spatial variability of precipitation was best simulated by the statistical models, as the regional models (with spatial resolution $\sim 50 \mathrm{~km}$ ) were not able to fully resolve the effects of the topography. Hellström \& Chen (2003) investigated whether statistical downscaling based on a regional model could further improve the seasonal cycle of precipitation, but concluded that the improvements were marginal compared to statistical downscaling directly from the global model. Concerning the seasonal temperature cycle, Hanssen-Bauer et al. (2003) concluded that this was reasonably well simulated by ECHc, except for a systematic overestimation of winter temperatures at sites which were exposed to temperature inversions during winter. The regional model improves the temperature estimates, but there is still a warm bias during winter in inland valleys. This bias is removed by the statistical method.

The above comparisons indicate that local climatic features caused by topographic structures that are not resolved by the global/regional models (e.g. ground temperature inversions and orographic precipitation effects) may be captured by statistical downscaling models.

But though statistical downscaling in some respects improves the description of the present climate, this is not a guarantee for improved projections of future climate changes. Several studies have demonstrated that unwise choices of predictors and domains may lead to dubious results (e.g. Benestad 1999, 2002a,b). Comparison of future scenarios downscaled by regional modelling and statistical downscaling may, however, form a basis for assessing the results. Hellström et al. (2001) compared results from regional modelling and statistical downscaling of precipitation from 2 different global models. They found that both global models and both downscaling techniques indicate increased precipita- 
tion over most of Sweden during autumn, and over NW Sweden during most of the year. In spring, regional modelling tended to also indicate a precipitation increase in southern Sweden, while statistical downscaling indicated a decrease. In summer, the results from the 2 global models differed for southern Sweden. The results were considered most reliable when there was an agreement between both global models and both downscaling techniques, i.e. increased precipitation in northern Sweden most of the year, and over most of Sweden during autumn.

Hanssen-Bauer et al. (2003) found significant differences between precipitation scenarios for Norway achieved by statistical downscaling and regional modelling only in summer in SW regions. This was probably due to the lack of a good 'signal bearing predictor' in the statistical model for the summer months. In autumn and winter, both methods indicated increased precipitation over most of the country. For temperature, no significant differences between the 2 approaches were found, though systematic differences were registered especially in winter and spring at inland localities. These could be explained by changes in ground temperature inversions which are not resolved by the regional model.

\section{FINAL DISCUSSION AND CONCLUSIONS}

Recent downscaling studies for Scandinavia show that statistical downscaling is a useful tool for developing local climate scenarios for this region. Though regional modeling usually is superior to statistical downscaling when it comes to the number of available variables, time resolution and consistency between different variables, statistical downscaling has several advantages. As stated by Benestad (2002b) and Chen et al. (2005), statistical downscaling usually requires less computer time than regional modelling and it is therefore possible to derive long time series and to explore the differences in multi-model ensembles. Benestad (2003b) showed that ensembles of statistically downscaled scenarios based on current GCMs can span most of the 20th century local temperature trends in Scandinavia, and that the multi-model ensemble mean is usually closer to the observed trend than any single model. It thus seems reasonable that similar multi-model ensembles can be used also to assess uncertainty as well as the most probable trend also in the future.

Another outstanding feature of statistical downscaling is its ability to deal with a variety of scales starting from the point/station scale, while dynamic downscaling is constrained by its resolution, which is presently around $50 \mathrm{~km}$ (Chen \& Li 2004). Statistical downscaling enables us to estimate changes in local climatic features which are not resolved by the regional models (Hanssen-Bauer et al. 2003), and to develop downscaling models for variables that are either not available or not realistically reproduced by regional models (Omstedt \& Chen 2001). Though statistical downscaling can be performed only for the limited number of localities with good observations, Benestad (2004a) and Skaugen \& Tveito (2004) showed how spatially detailed climate maps may be produced by using Geographical Information System (GIS) methodology to combine local statistically downscaled climate scenarios and geographical elements such as altitude, longitude, latitude and distance from the coast.

Statistical downscaling must still be applied with care, and it is particularly important that the climate change signal is included among the predictors in the statistical models. The Scandinavian studies indicate that large-scale T2 or T850 can be used as signal bearing predictors for $T 2$. When downscaling precipitation it is crucial to include humidity information from the troposphere. Large-scale $q 850$ may be applied for this purpose (Hellström et al. 2001), though Linderson et al. (2004) concluded that large-scale $R$ is better. This seems reasonable, as large-scale $R$ probably represents the precipitable water better than the humidity at one specific level does. But the predictors' performances in the final downscaling models also depend on how well the climate models simulate the respective large-scale fields. One should thus validate the global models with respect to $q 850$ and $\mathrm{R}$ before drawing a final conclusion. In any case, it is necessary to also include atmospheric circulation information among the predictors for $R$.

In spite of somewhat differing warming rates, the statistically downscaled temperature scenarios for Scandinavia show several similarities (Benestad 2002a,b, 2004a, Hanssen-Bauer et al. 2003). The local warming rates tend to be higher in winter than in summer and larger inland than along the coast. Several models also show higher warming rates at higher latitudes, but the coast-inland gradient is dominating. Comparison of temperature scenarios for localities with different altitude indicate a possibility for weaker temperature inversions during winter in the future. According to some model integrations, a fraction of the winter warming is associated with changes in the atmospheric circulation (Benestad 2001a, HanssenBauer \& Førland 2001). The major part of the warming is, however, not connected to this change.

The precipitation scenarios for Scandinavia are less consistent than the temperature scenarios. A considerable part of the projected changes in a given integration is associated with projected changes in atmospheric circulation (Hellström et al. 2001, Hanssen-Bauer et al. 2003, Linderson et al. 2004), 
which differs from model to model (Benestad 1999, Chen et al. 2005). There are still some common features. According to most models, annual precipitation in Scandinavia is projected to increase partly because of an increase in the average westerly wind component, but mostly due to the general increase in the precipitable water over the area (Hanssen-Bauer et al. 2001, Hellström et al. 2001, Chen et al. 2005). Most models show precipitation increase in autumn and winter, and for northern regions also in spring. In summer several models show negative precipitation trends in southern Scandinavia, but the level of confidence is smaller in summer than in winter. A study from southern Sweden indicates that the frequency of wet days in summer may be reduced more than the mean precipitation (Linderson et al. 2004). Thus precipitation intensity for rainy days may increase all year around.

Comparison of climate scenarios resulting from regional modelling and statistical downscaling based upon the same global scenario show several common features, but also a few differences. Some differences are supposedly connected to local phenomena that are not resolved by the regional models. Other differences are probably connected to known shortcomings of the statistical models. But there are also differences without obvious explanations, which may be due to shortcomings of either of the downscaling models and/or of the global climate model. Thus, inconsistencies between the results may point to more general modelling problems. With precipitation, for example, the main differences between scenarios from regional modelling and statistical downscaling occur in spring/ summer, when Busuioc et al. (2001b) showed that the observed links between the SLP field and $R$ over Sweden are not satisfactorily reproduced by HadCM2. On the other hand, consistency between results from these very different downscaling approaches adds confidence to the results.

We can see several challenges and possibilities concerning improving existing downscaling models, improving the time resolution and developing models for other variables. Some impacts of climatic changes depend more on extremes than mean values. Assessing such impacts thus depends on at least daily time resolution, and the potential in Scandinavia for application of the analogue technique as well as weather generators is presently being explored. In impact research there is also a need for local scenarios for additional variables, especially wind, snow/ice cover and cloud conditions. Different possibilities for meeting these demands are being explored, including purely statistical approaches as well as statistical refinement of output from regional models. Both regional modelling and statistical downscaling and adaptation will be necessary in order to assess the impacts of the projected climate changes.

\section{LITERATURE CITED}

Benestad RE (1999) Pilot studies of enhanced greenhouse gas scenarios for Norwegian temperature and precipitation from empirical downscaling. Klima Rep 16/99, Norwegian Meteorological Institute, Oslo

Benestad RE (2001a) The cause of warming over Norway in the ECHAM4/OPYC3 GHG integration. Int J Climatol 21: 371-387

Benestad RE (2001b) A comparison between 2 empirical downscaling strategies. Int J Climatol 21:1645-1668

Benestad RE (2002a) Empirically downscaled climate scenarios for northern Europe. Clim Res 21:105-125

Benestad RE (2002b) Empirically downscaled multi-model ensemble temperature and precipitation scenarios for Norway. J Clim 15:3008-3027

Benestad RE (2003a) clim.pact-V1.0. Klima Rep 04/03, Norwegian Meteorological Institute, Oslo

Benestad RE (2003b) What can present climate models tell us about climate change? Clim Change 59:311-332

Benestad RE (2003c) How often can we expect a recordevent? Clim Res 25:3-13

Benestad RE (2004a) Tentative probabilistic temperature scenarios for northern Europe. Tellus 56A:89-101

Benestad RE (2004b) Empirical-statistical downscaling in climate modeling. EOS 85(42):417

Benestad RE (2004c) Empirically downscaled SRES-based climate scenarios for Norway. Met-no rep, 08-2004, Norwegian Meteorological Institute, Oslo

Benestad RE, Hanssen-Bauer I, Førland EJ, Iden K, Tveito OE (1999) Evaluation of monthly mean data fields from the ECHAM4/OPYC3 control integration. Klima Rep 14/99, Norwegian Meteorological Institute, Oslo

Benestad RE, Førland EJ, Hanssen-Bauer I (2002) Empirically downscaled temperature scenarios for Svalbard. Atmos Sci Lett; doi.10.1006/asle.2002.005

Bergström S, Carlsson B, Gardelin M, Lindström G, Pettersson A, Rummukainen M (2001) Climate change impacts on runoff in Sweden - assessments by global climate models, dynamical downscaling and hydrological modeling. Clim Res 16:101-112

Blenckner T, Chen D (2003) Comparison of the impact of regional and North Atlantic atmospheric circulation on an aquatic ecosystem. Clim Res 23:131-136

Boer GJ, Flato G, Ramsden D (2000) A transient climate change simulation with greenhouse gas and aerosol forcing: projected climate to the twenty-first century. Clim Dyn 16(6):424-450

Briffa KR (1995) The simulation of weather types in GCMs: a regional approach to control-run validation. In: von Storch H, Navarra A (eds) Analysis of climate variability. Springer, Berlin, p 122-138

Busuioc A, Chen D, Hellström C (2001a) Temporal and spatial variability of precipitation in Sweden and its link with the large scale atmospheric circulation. Tellus 53A(3):348-367

Busuioc A, Chen D, Hellström C (2001b) Performance of statistical downscaling models in GCM validation and regional climate estimates: application for Swedish precipitation. Int J Climatol 21:557-578

Chen D (2000) A monthly circulation climatology for Sweden and its application to a winter temperature case study. Int J Climatol 20:1067-1076

Chen D, Chen Y (1999) Development and verification of a multiple regression downscaling model for monthly temperature in Sweden. In: Chen D, Hellström C, Chen Y (eds) Preliminary analysis and statistical downscaling of monthly temperature in Sweden. Report C16, Earth Sci- 
ences Centre, University of Gothenburg, Gothenburg, p 41-55

Chen D, Hellström C (1999) The influence of the North Atlantic Oscillation on the regional temperature variability in Sweden: spatial and temporal variations. Tellus 51A(4):505-516

Chen D, Li X (2004) Scale dependent relationship between maximum ice extent in the Baltic Sea and atmospheric circulation, Global Planet Change 41:275-283

Chen D, Omstedt A (2005) Climate-induced variability of sea level in Stockholm: influence of air temperature and atmospheric circulation. Adv Atmos Sci 22:655-664

Chen D, Achberger C, Räisänen J, Hellström C (2005) Using statistical downscaling to quantify the GCM-related uncertainty in regional climate change scenarios: a case study of Swedish precipitation. Adv Atmos Sci (in press)

Cubasch U, Hasselmann K, Hock H, Maier-Reimer E, Mikolajewicz U, Santer BD, Sausen R (1992) Time-dependent greenhouse warming computations with a coupled oceanatmosphere model. Clim Dyn 8:55-69

Fan L, Fu C, Chen D (2005) A survey on statistical downscaling in climate studies. Adv Earth Sci 20(3):320-329 (in Chinese with English abstract)

Flato GM, Boer GJ, Lee WG, McFarlane NA, Ramsden D, Reader MC, Weaver AJ (2000) The Canadian Centre of Climate Modelling and Analysis global coupled model and its climate. Clim Dyn 16(6):451-467

Førland EJ, Skaugen TE, Benestad RE, Hanssen-Bauer I, Tveito OE (2004) Variations in thermal growing, heating and freezing indices in the Nordic Arctic 1900-2050. Arct Antarct Alp Res 36(3):346-355

Gibson JK, Kållberg P, Uppala S, Hernandez A, Nomura A, Serrano E (1997) ERA description. ECMWF Reanalysis Project Rep. Series 1, European Centre for Medium Range Weather Forecasts, Reading

Giorgi F, Hewitson B, Christensen JH, Hulme M and 5 others (2001) Regional climate information - evaluation and projections. In: Houghton JT, Ding Y, Griggs DJ, Noguer M, van der Linden PJ, Dai X, Maskell K, Johnson CA (eds) Climate change 2001: the scientific basis. Contribution of Working Group I to the Third Assessment Report of the Intergovernmental Panel on Climate Change. Cambridge University Press, Cambridge, p 583-638

Hanssen-Bauer I, Førland EJ (2000) Temperature and precipitation variations in Norway 1900-1994 and their links to atmospheric circulation. Int J Climatol 20(14):1693-1708

Hanssen-Bauer I, Førland EJ (2001) Verification and analysis of a climate simulation of temperature and pressure fields over Norway and Svalbard. Clim Res 16:225-235

Hanssen-Bauer I, Tveito OE, Førland EJ (2001) Precipitation scenarios for Norway. Empirical downscaling from ECHAM4/OPYC3. Klima Rep 10/01, Norwegian Meteorological Institute, Oslo

Hanssen-Bauer I, Førland EJ, Haugen JE, Tveito OE (2003) Temperature and precipitation scenarios for Norway: comparison of results from dynamical and empirical downscaling. Clim Res 25:15-27.

Hellström C, Chen D (2003) Statistical downscaling based on dynamically downscaled predictors: application to monthly precipitation in Sweden. Adv Atmos Sci 20: 951-958.

Hellström C, Chen D, Achberger C, Räisänen J (2001) Comparison of climate change scenarios for Sweden based on statistical and dynamical downscaling of monthly precipitation. Clim Res 19:45-55.

Imbert A, Benestad RE (2005) An improvement of analog model strategy for more reliable local climate change sce- narios. Theor Appl Clim 82:245-255

Johns TC, Carnell RE, Crossley JF, Gregory JM, Mitchell JBF, Senior CA, Tett SBF, Wood RA (1997) The second Hadley Centre coupled ocean-atmosphere GCM: model description, spinup and validation. Clim Dyn 13:103-134

Kaas E, Frich P (1995) Diurnal temperature range and cloud cover in the Nordic countries: observed trends and estimates for the future. Atmos Res 37:211-228

Kalnay E, Kanamitsu M, Kistler R, Collins W and 18 others (1996) The NCEP/NCAR 40-year reanalysis project. Bull Am Meteorol Soc 77:437-471

Kattenberg A, Gruza GV, Jouzel J, Karl TR, Ogallo LA, Parker DE (1996) Observed climate variability and change. In: Houghton JT, Meira Filho LG, Callander BA, Harris N, Kattenberg A, Maskell K (eds) Climate change 1995 — the science of climate change. Cambridge University Press, Cambridge, p 289-357

Kistler R, Kalnay E, Collins W, Saha S and 8 others (2001) The NCEP-NCAR 50-year reanalysis: monthly means CDROM and documentation. Bull Am Meteorol Soc 82: $247-268$

Lamb HH (1950) Types and spells of weather around the year in the British Isles. Q J R Meteorol Soc 76:393-438

Liao Y, Zhang Q, Chen D (2004) Stochastic modeling of daily precipitation in China. J Geogr Sci 14(4):417-426

Linderson ML, Achberger C, Chen D (2004) Statistical downscaling and scenario construction of precipitation in Scania, southern Sweden. Nord Hydrol 35:261-278

McAvaney BJ, Covey C, Joussaume S, Kattsov V and 6 others (2001) Model evaluation. In: Houghton JT, Ding Y, Griggs DJ, Noguer M, van der Linden PJ, Dai X, Maskell K, Johnson CA (eds) Climate change 2001: the scientific basis. Contribution of Working Group I to the Third Assessment Report of the Intergovernmental Panel on Climate Change. Cambridge University Press, Cambridge, $\mathrm{p} 471-523$

Meehl GA, Boer GJ, Covey C, Latif M, Stouffer RJ (2000) The Coupled Model Intercomparison Project (CMIP). Bull Am Meteorol Soc 81:313-318

Nakićenović N, Alcamo J, Davis B, de Vries J and 24 others (2000) IPCC special report on emission scenarios. Cambridge University Press, Cambridge

New M, Hulme M, Jones P (1999) Representing twentiethcentury space-time climate variability. Part I: Development of a 1961-90 mean monthly terrestrial climatology. J Clim 12:829-856

New M, Hulme M, Jones P (2000) Representing twentiethcentury space-time climate variability. Part II: Development of 1901-96 monthly grids of terrestrial surface climate. J Clim 13:2217-2238

North GR, Bell TL, Cahalan RF (1982) Sampling errors in the estimation of empirical orthogonal functions. Mon Weather Rev 110:699-706

Oberhuber JM (1993) Simulation of the Atlantic circulation with a coupled sea ice-mixed layer-isopycnal general circulation model. Part I. Model description. J Phys Oceanogr 22:808-829

Omstedt A, Chen D (2001) Influence of atmospheric circulation on the maximum ice extent in the Baltic Sea. J Geophys Res 106(C3):4493-4500

Reichert BK, Bengtsson L, Åkesson O (1999) A statistical modeling approach for the simulation of local paleoclimatic proxy records using GCM output. J Geophys Res 104(D16):19071-19083

Roeckner E, Arpe K, Bengtsson L, Christof M and 6 others (1996) The atmospheric general circulation model ECHAM4: model description and simulation of present- 
day climate. Report No 218, Max-Planck-Institut für Meteorologie, Hamburg

Roeckner E, Bengtsson L, Feichter J, Lelieveld J, Rodhe H (1999) Transient climate change simulations with a coupled atmosphere-ocean GCM including the tropospheric sulfur cycle. J Clim 12:3004-3032

Rummukainen $\mathrm{M}$, Räisänen J, Bringfelt B, Ullerstig A, Omstedt A, Willén U, Hansson U, Jones C (2001) A regional climate model for northern Europe: model description and results from the downscaling of 2 GCM control simulations. Clim Dyn 17:339-359

Seidel DJ, Angel JK, Christy J, Free M and 9 others (2004) Uncertainty in signal of large-scale climate variations in radiosonde and satellite upper-air temperature datasets. J Clim 17:2225-2239

Skaugen TE, Tveito OE (2004) Growing season and degree-day scenario in Norway for 2021-2050. Clim Res 26:221-232

Editorial responsibility: Robert Davis,

Charlottesvillle, Virginia, USA
Varis O, Kajander T, Lemmelä R (2004) Climate and water: from climate models to water resources management and vice versa. Clim Change 66:321-344

von Storch H, Hewitson B, Mearns L (2000) Review of empirical downscaling techniques. In: Iversen T, Høiskar BAK (eds) Regional climate development under global warming. General Tech Rep 4, Norwegian Meteorological Institute, Oslo, p 29-46

Wetterhall F, Halldin S, Xu CY (2005) Statistical precipitation downscaling in central Sweden with the analogue method. J Hydrol 306:174-190

Wilby RL, Wigley TML (1997) Downscaling general circulation model output: a review of methods and limitations. Prog Phys Geogr 21:530-548

Zorita E, von Storch H (1999) The analogue method as a simple statistical downscaling technique: comparison with more complicated methods. J Clim 12:2474-2488

Submitted: April 29, 2005; Accepted: September 22, 2005

Proofs received from author(s): October 11, 2005 